\title{
Intermediate-Term Outcomes of 3F Stentless Bioroot for Bentall Operation
}

\author{
Guglielmo Stefanelli ${ }^{1 *}$, Fabrizio Pirro ${ }^{1}$, Luigi Steffanon ${ }^{1}$, Alessandro Bellisario ${ }^{2}$ and Luca Weltert ${ }^{2,3}$ \\ ${ }^{1}$ Department of Cardiac Surgery, Cardiology and Cardiac Anaesthesia, Hesperia Hospital, Modena, Italy \\ ${ }^{2}$ Department of Cardiac Surgery, European Hospital, Rome, Italy \\ ${ }^{3}$ Department of Biostatistics, Saint Camillus International University of Health Sciences, Rome, Italy
}

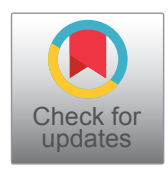

*Corresponding author: Guglielmo Stefanelli, Department of Cardiac Surgery, Cardiology and Cardiac Anaesthesia, Hesperia Hospital, via Arquà 80/A, Modena (IT), Italy, Tel: +39-059449259, +39-3296326970

\begin{abstract}
Background: Aim of this study was to assess the intermediateterm outcome after Bentall operation using a self-assembled bio-root conduit containing a $3 \mathrm{~F}$ stentless valve.

Methods: Between April 2010 and August, 2015, 30 patients affected by aortic root dilatation with aortic valve disease underwent Bentall operation at our Unit, using a conduit assembled by including a $3 \mathrm{~F}^{\circledR}$ stentless valve into a straight woven tube graft. Mean age at surgery was 66.3 yrs. Mean Logistic EUROscore was 10.01. Mean pre-operative Ejection Fraction was $54.50 \%$. Two patients $(6.3 \%)$ had undergone a previous operation. Three patients $(10 \%)$ had a bicuspid valve. Five patients $(16.6 \%)$ received an associate procedure. Mean size of bio-root was 28.93. Mean ischemic time was 101.43', mean CPB time 127'.

Results: All patients were evaluated by echocardiogram and clinical examination at discharge and annually. Median follow-up time was 6.94 years. Primary end points of our analysis consisted of early and late mortality, freedom from $A B E$ and MACCE, freedom from SVD and freedom from valve-related reoperation. Early mortality was $0 \%$. Two patients died during follow-up, one for cardiac causes. Survival probability at 10 years was $93.1 \%$. Freedom from $A B E$ at 10 years was $100 \%$. Freedom from SVD was $87.5 \%$ at 10 years. Freedom from valve-related reoperation was $96.6 \%$ at 10 years. Incidence of MACCE was $79 \%$ at 10 years. Mean gradient at follow-up was $11.9 \mathrm{mmHg}$.

Conclusions: 3F composite stentless bioroot has represented a valid option for Bentall operation. Rate of valve-related complications and durability are satisfactory. Hemodynamic performances are adequate and preserved over time.
\end{abstract}

\section{Keywords}

Aortic valve replacement, Stentless valve, Aortic root replacement

\section{Background}

Tissue valves represent now a days the most frequent choice for aortic valve replacement, even in younger patients. Among the several bioprostheses available on the market, stentless valves, despite proven excellent hemodynamics, are used quite infrequently by surgeons, mainly due to more complex implantation technique, if compared to stented prostheses, and to their questionable durability. The idea to construct a valved bioroot suitable for Bentall operation using stentless prosthesis is not new. Biointegral conduit ${ }^{\circledR}$ (Biointegral Surgical Inc, Mississauga, Canada), a full biological valved conduit and BioValsalva ${ }^{\circledR}$ (Vascutek Terumo, Renfrewshire, Scotland, UK), a Valsalva graft containing a porcine stentless valve are an example of two ready-to-use devices available on the market and commonly employed. We analyzed in this study our experience with a self-assembled bio-root constructed by inclusion of a Medtronic (Medtronic Inc, Minneapolis, USA) $3 F^{\circledR}$ stentless aortic valve into a straight woven tube graft. This assembly was originally described by Stewart, et al. in 2010. Unlike Stewart's conduit, our bio-root consisted of a straight tube graft instead of a Valsalva graft, constructed in a slightly different way. Since $3 \mathrm{~F}$ is true stentless prosthesis, it is possible to include it in a conduit only one size bigger than the valve, considerably improving the hemodynamic performances. We have implanted the $3 F$ bioroot in 30 patients with aortic root dilatation and aortic valve disease with encouraging results from 2010 until 2015,

Citation: Stefanelli G, Pirro F, Steffanon L, Bellisario A, Weltert L (2021) Intermediate-Term Outcomes of 3F Stentless Bioroot for Bentall Operation. Int J Clin Cardiol 8:233. doi.org/10.23937/23782951/1410233

Accepted: July 21, 2021: Published: July 23, 2021

Copyright: (C) 2021 Stefanelli G, et al. This is an open-access article distributed under the terms of the Creative Commons Attribution License, which permits unrestricted use, distribution, and reproduction in any medium, provided the original author and source are credited. 
when the prosthesis was withdrawn from the market. We aimed to review our experience with the $3 \mathrm{~F}$ bioroot in Bentall operation, to discuss its easiness of construction and implantation, and to analyze the early and intermediate-term outcomes concerning mortality, durability, incidence of valve-related complications and hemodynamic performances over time.

\section{Methods}

\section{Population}

Between April, 2010 and August, 2015 a cohort of 30 patients underwent at our institution a Bentall operation using a self-assembled $3 \mathrm{~F}$ bio-root conduit by a single surgeon. 26 patients were males, mean age at surgery was $66.26 \pm 10.33$ years (range 43 to 80 years). Indication for Bentall operation was a severe dilatation of the aortic root associated to aortic valve disease not suitable for aortic root sparing procedures. During the same timeframe 21 patients underwent a David reimplantation procedure and 4 patients received a mechanical Bentall operation. For younger patients, the biological device was chosen at explicit and informed patient's request, usually to avoid the need for anticoagulation. Exclusion criteria were: emergency surgery, acute aortic dissection and the presence of heavily calcified aortic root. Pre-operative mean Logistic EUROscore was $10.1 \pm 4.37$ (range: 3.1419.74). Two patients (6.67\%) had undergone a previous cardiac operation. In 3 cases (10\%), the aortic valve was bicuspid. Pre-operative mean Ejection Fraction (EF) was $54 \pm 9.04 \%$ (range: $25 \%-65 \%$ ). Mean LV End Diastolic Diameter (LVEDD) was $55.33 \pm 8.16 \mathrm{~mm}$ (range: $42-80$ $\mathrm{mm}$ ). $30 \%$ of patients were in NYHA Class III-IV before operation, the remaining were in Class II. Mixed aortic valve pathology was present in $15 \%$ of cases, isolated aortic stenosis in $20 \%$, and isolated aortic incompetence in the remaining. Associated cardiac disorders were present in 5 patients (16.6\%), and included coronary artery disease in 4 and mitral valve incompetence in one. Pre-operative patient's characteristics are illustrated in Table 1.

\section{Surgical technique}

The surgical technique adopted in all cases was the 'button bentall' operation as originally described by

Table 1: Preoperative and peri-operative patient's characteristics.

\begin{tabular}{|c|c|c|c|c|c|}
\hline & Mean & St. D. & Min-Max & $\mathbf{N}^{\circ}$ & $\%$ \\
\hline Age & 66.3 & 10.3 & $43-80$ & 30 & \\
\hline $\mathrm{BSA}\left(\mathrm{m}^{2}\right)$ & 1.9 & 0.2 & $1.54-2.26$ & & \\
\hline Gender (male) & & & & 26 & $86.67 \%$ \\
\hline Additive Euroscore & 7.4 & 1.7 & $4-10$ & & \\
\hline Logistic Euroscore & 10.0 & 4.4 & $3.14-19.74$ & & \\
\hline NYHA Class I & & & & 0 & $0 \%$ \\
\hline NYHA Class II & & & & 21 & $70.0 \%$ \\
\hline NYHA Class III & & & & 8 & $26.7 \%$ \\
\hline NYHA Class IV & & & & 1 & $3.3 \%$ \\
\hline Urg/Emerg surgery & & & & 0 & $0.0 \%$ \\
\hline Previous Cardiac Surgery & & & & 2 & $6.7 \%$ \\
\hline ABE pre-op & & & & 0 & $0.0 \%$ \\
\hline Bicuspid Valve & & & & 3 & $10.0 \%$ \\
\hline Degenerative Aetiology & & & & 30 & $100.0 \%$ \\
\hline EF pre-op (\%) & $54 \%$ & $9 \%$ & $25-65$ & & \\
\hline EDD pre-op (mm) & 55.3 & 8.2 & $42-80$ & & \\
\hline Associated Procedures (All) & & & & 5 & $16.6 \%$ \\
\hline CABG & & & & 4 & $13.3 \%$ \\
\hline Mitral Repair & & & & 1 & $3.3 \%$ \\
\hline Bioroot Size 28 (mm) & & & & 16 & $53.3 \%$ \\
\hline Bioroot Size 30 (mm) & & & & 14 & $46.6 \%$ \\
\hline ECC (min) & 127.0 & 35.4 & $84-236$ & & \\
\hline ACC (min) & 101.4 & 26.1 & $71-158$ & & \\
\hline ICU Stay (hours) & 30.2 & 18.1 & $16-90$ & & \\
\hline EF at discharge $\%$ & 54.1 & 8.1 & $35-65$ & & \\
\hline Peak Grad. at discharge $(\mathrm{mmHg})$ & 20.0 & 6.1 & $11-39$ & & \\
\hline
\end{tabular}




\begin{tabular}{|c|c|c|c|c|c|}
\hline Mean Grad. at discharge (mmHg) & 12.4 & 8.6 & $6-17$ & & \\
\hline EDD at discharge (mm) & 54.1 & 7.2 & $42-75$ & & \\
\hline Thrombocytopenia post-op & & & & 8 & $26.7 \%$ \\
\hline Mediastinitis & & & & 1 & $3.3 \%$ \\
\hline Complications (overall) & & & & 1 & $3.3 \%$ \\
\hline Intra-op mortality & & & & 0 & $0.0 \%$ \\
\hline
\end{tabular}

BSA: Body Surface Area; NYHA: New York Heart Association; ABE: Acute Bacterial Endocarditis; EF: Ejection Fraction; IVS: Interventricular Septum; EDD: End Diastolic Diameter; CABG: Coronary Artery Bypass Graft; ECC: Extracorporeal Circulation; ACC: Aortic Cross-Clamping; ICU: Intensive Care Unit

Kouchoukos in 1991 [1]. The conduit was self-assembled by the surgeon on the back table, in the last cases using a modified $3 \mathrm{~F}$ holder with its handle sticked into a $30 \times$ $20 \mathrm{~cm}$. rigid plastic base to facilitate the construction.

As a first step the tube graft size was selected, based on repeated intraoperative transesophageal echo (TEE) measurements of aortic annulus and ventriculo-aortic junction. In cases of calcified aortic valve three sizes were added to the calculated one.

As a result, $28 \mathrm{~mm}$ or $30 \mathrm{~mm}$ have been the two graft sizes chosen for all patients, along with a $3 \mathrm{~F}$ valve one $\mathrm{mm}$. smaller than the tubular prosthesis. Subsequently to $1 \mathrm{~cm}$ external folding of its proximal edge, the graft was inserted over the upside-down prosthesis attached to its handle. Three temporary 4-0 polypropylene single stitches at $120^{\circ}$ fixed the valve sewing cuff to the graft folded edge. Next, three 4-0 polypropylene continuous running sutures secured the prosthesis cuff to the graft, the temporary stitches were removed and the folded graft skirt was straighten up. The valve holder was then removed and the three prosthetic commissural tabs were positioned and attached to the graft wall by three 4-0 polypropylene stitches per tab, using the three reference markers at $120^{\circ}$ of the graft. Care must be taken to avoid pulling of the graft during this maneuver.

In the last 10 cases the bio-root was assembled prior to start the extracorporeal circulation (ECC), thus reducing considerably its duration. All operations were performed by median sternotomy, standard ECC at $34^{\circ} \mathrm{C}$, aortic cross-clamping (ACC) and cold cardioplegic arrest, by antegrade or retrograde infusion of Custodiol ${ }^{\circledast}$ solution. After transverse aortotomy and excision of the aortic wall and native valve, the two coronary buttons were prepared. In cases of calcified aortic annulus an accurate debridement was carried out. The proximal side of the graft, usually tailored to 0.5-0.6 mm below the valve, was secured to the left ventricular outflow by interrupted pledgeted mattress 2-0 braided polyester sutures, taking care not to shrink the aortic annulus. The coronary ostia were reimplanted using continuous 5-0 polypropylene sutures and the distal part of the graft was anastomosed to the divided aorta on a teflon strip reinforcement by a continuous 4-0 polypropylene suture. In case of future prosthetic replacement for structural valve deterioration (SVD), only the valve leaflets removal would be necessary, using the prosthetic sewing cuff as a support for the new device implant, thus avoiding a new Bentall procedure. For the first days after surgery a dosage of subcutaneous low-molecular-weight heparin adjusted for body weight was given to all patients, followed by administration of low-dosage aspirin and statins for one year after hospital discharge. Oral anticoagulation with vitamin $\mathrm{K}$ antagonist was chosen for patients with history of atrial fibrillation or receiving an associated procedure involving the mitral valve. Routine coronary angiography along with echocardiographic evaluation was carried out in all patients before operation.

\section{Follow-up}

The follow-up ranged between 1.09 and 10.18 years (median follow-up time: 6.94 yrs-in total: 203.98 $\mathrm{pt} / \mathrm{year}$ ) and it was $100 \%$ complete. All patients were followed by clinical and echocardiographic evaluation at discharge and at regular follow-up controls, according to a standardized protocol shared with the patient's referring cardiologist. Cardiac and non cardiac causes of death and cases of major adverse cardiac and cerebrovascular events (MACCE), structural valve deterioration (SVD) and valve-related reoperation were accurately recorded. A mean gradient higher than 20 $\mathrm{mmHg}$ and/or valve incompetence greater than $3+$ were considered markers for SVD. The study was approved by the Institutional Ethical Committee (HH Healthcare EC. \# 008/2019). Preoperative, perioperative and postoperative data were collected from the hospital medical records and informed consent to use their data was obtained from all the patients. Guidelines reported by Akins et al were used to define the endpoints of the analysis.

\section{Statistical Analysis}

Data entry was carried out prospectively into the Clincal Database and then extracted to csv file in order to import into statistical suites. The statistical analysis was performed using SPSS (Release 20 IBM Corporation) and MedCalc 14.8 (MedCalc Software bvba). Completeness of follow up was $100 \%$. All specified variables that describe demographic and other characteristics were summarized either by central tendency and dispersion measures (if continuous, after testing for normality to choose either mean and standard deviation or median 
and interquartile range with Shapiro-Wilk test) or absolute occurrence and percentage (if discrete), as appropriate. Where significant upper and lower limits are specified too. After testing for normal distribution either T-test or Kruskal-Wallis or Mann-Withney tests were used to compare continuous variables, while either X-square or Fisher Test where used to compare discrete variables. Cumulative survival and freedom from events were estimated using the Kaplan-Meier method and 95\% confidence intervals using the Greenwood's formula. Number at risk is stated at each timeframe on graphics while sidelines for confidence intervals are plotted as thin lines for sake of clarity. Log Rank method was used to test differences among time dependent variables. A Cox regression model was used to investigate the impact of factors on time-dependent end-points. P-value of $<0.05$ was considered statistically significant.

\section{Results}

Concomitant procedures were performed in 5 patients $(16.6 \%)$, coronary artery bypass grafting in 4 $(13.3 \%)$, mitral valve repair in one $(3.3 \%)$. The size of implanted bio-root was $30 \mathrm{~mm}$ in 14 and $28 \mathrm{~mm}$ in 16 cases. The size of $3 \mathrm{~F}$ prosthesis was respectively $29 \varnothing$ in 14 and $27 \varnothing$ in 16 cases. The mean ECC time was $127 \pm$ $35 \mathrm{~min}$ (range: 84-236 min). The mean ACC time was 101 \pm 26 min (range: $71-158 \mathrm{~min}$ ). For isolated procedures mean ACC time was $86.4 \mathrm{~min}$. Mean intensive care unit length of stay (LOS) was $30.23 \pm 18.13$ hours (range: 16 90 hours). Transient thrombocytopenia was observed in 8 patients $(26.67 \%)$, in all cases with return to values within normal range before hospital discharge. One patient developed an early sternal infection with mediastinitis following surgical re-exploration for bleeding and was treated with local medications and systemic antibiotic therapy. After full recovery he was discharged home, after sternal closure, in excellent conditions. Peak transvalvular gradient at hospital discharge was $20.03 \pm 6.09 \mathrm{mmHg}$ (range $11-39 \mathrm{mmHg}$ ).
Mean gradient was $12.37 \pm 8.64 \mathrm{mmHg}$ (range $6-17$ $\mathrm{mmHg}$ ). All patients were discharged from hospital in good clinical conditions. 30 days - hospital mortality was $0 \%$ for the entire cohort. Intra and post-operative details are reported in Table 1.

Twenty-eight patients were alive at last follow-up. Overall survival probability was 93.15 at 5 and 9 years. No patient died for cardiac causes during follow-up (Figure 1). One patient died for acute complication of diabetes few months after operation, another died five years later for complications of Alzheimer disease. Freedom from acute bacterial endocarditis (ABE) was $100 \%$ at 9 years follow-up. Freedom from MACCE, including reoperation, was $93.2 \%$ at 5 years and $84.5 \%$ at 9 years (Figure 2). One patient underwent a pace-maker (PMK) implant two months after operation. It was the case of a patient with a degenerated bioprosthesis and a seconddegree block at pre-operative electrocardiogram. Mean New York Heart Association (NYHA) Class at discharge was 1.17; 5 patients were in Class II, the remaining in Class I. In 6 cases (20\%), a +1 degree central aortic incompetence was diagnosed by echo at follow-up. Follow-up data are illustrated in Table 2.

Freedom from SVD was $100 \%$ at 5 years, $87.5 \%$ at 9 years (87.5\%). Freedom from valve related reoperation was $96.6 \%$ at 5 and at 9 years follow-up (Figure 3). Left ventricular end-diastolic diameter (LVEDD) diameter significantly improved if compared to pre-operative ( $p$ $=0.002)$ (Figure 4A). A Mean transvalvular gradient at last follow-up was $11.93 \pm 4.95$ (range $5-27 \mathrm{mmHg}$ ), including the case of SVD. No statistical difference was found with respect to the hospital discharge data (Figure 4B).

\section{Discussion}

Use of biological conduits for Bentall operation [2] has increased in recent years parallel to that of aortic valve prostheses. Despite patient's aging and avoidance of lifelong anticoagulation are important explanations
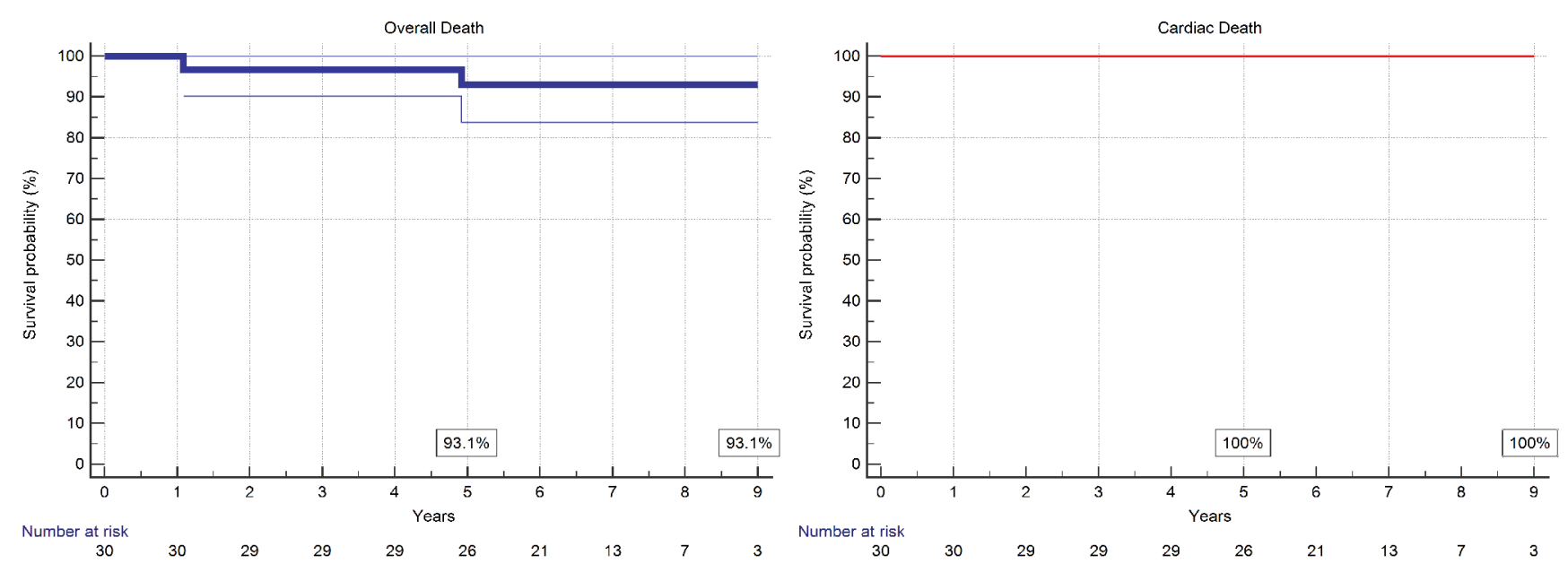

Figure 1: Overall and cardiac deaths. 

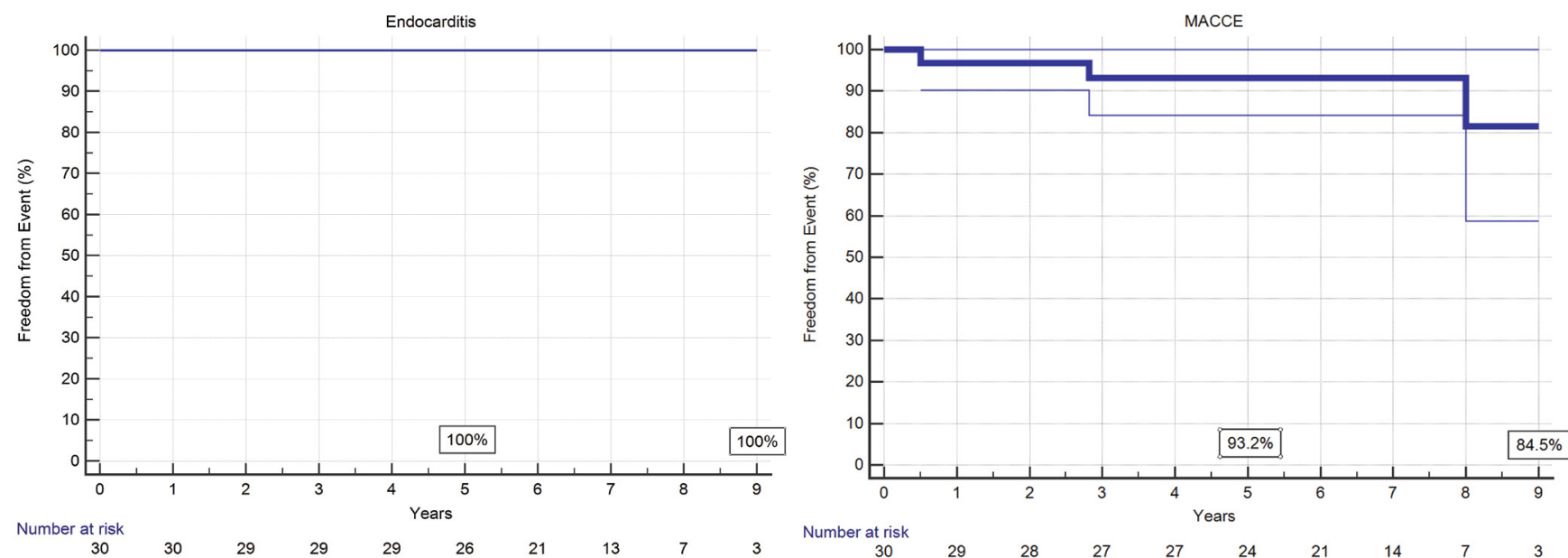

Figure 2: Incidence of bacterial endocarditis and MACCE.

Table 2: Follow-up data.

\begin{tabular}{|l|l|l|l|l|l|}
\hline & Mean & St. D. & Min-Max & $\mathbf{N}^{\circ}$ & $\%$ \\
\hline Early (30 days-Hosp) deaths & & & & 0 & $0.0 \%$ \\
\hline Overall late deaths & & & & 2 & $6.7 \%$ \\
\hline Late cardiac deaths & & & & 0 & $0.0 \%$ \\
\hline Median F-up time (yrs) & 6.9 & & $1.09-10.18$ & & \\
\hline EF at F-up \% & 56 & 6.7 & $35-65$ & & \\
\hline Peak Gradient at F-up & 21.1 & 7.9 & $10-50$ & & \\
\hline Mean Gradient at F-up & 11.9 & 4.6 & $5-27$ & & \\
\hline EDD at F-up (mm) & 51.4 & 5.8 & $42-65$ & 0 & $0.0 \%$ \\
\hline MACCE & & & & 1 & $3.3 \%$ \\
\hline ABE & & & & 1 & $3.3 \%$ \\
\hline SVD & & & & 1 & $3.3 \%$ \\
\hline PMK implantation & & & & 6 & $20 \%$ \\
\hline Valve-related Reop. & & & & 0 & $0.0 \%$ \\
\hline AR at F-up (mild) & & & $0-1$ & & \\
\hline AR at F-up (mod-severe) & & & & \\
\hline
\end{tabular}

F-up: Follow-up; EF: Ejection Fraction; EDD: End-Diastolic Diameter; IVS: Interventricular Septum; MACCE: Major Adverse Cardiac and Cerebrovascular Events; ABE: Acute Bacterial Endocarditis; SVD: Structural Valve Deterioration; PMK: Pace-Maker; AR: Aortic Regurgitation
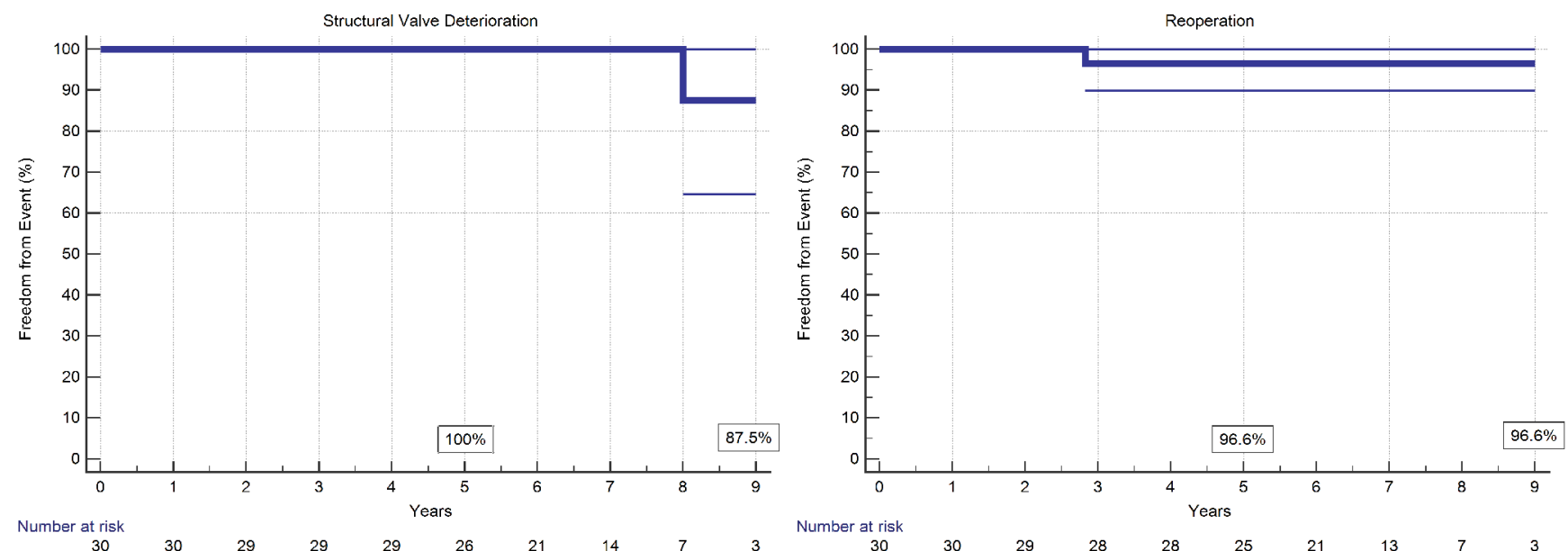

Figure 3: Incidence of structural valve deterioration and valve-related reoperative surgery. 


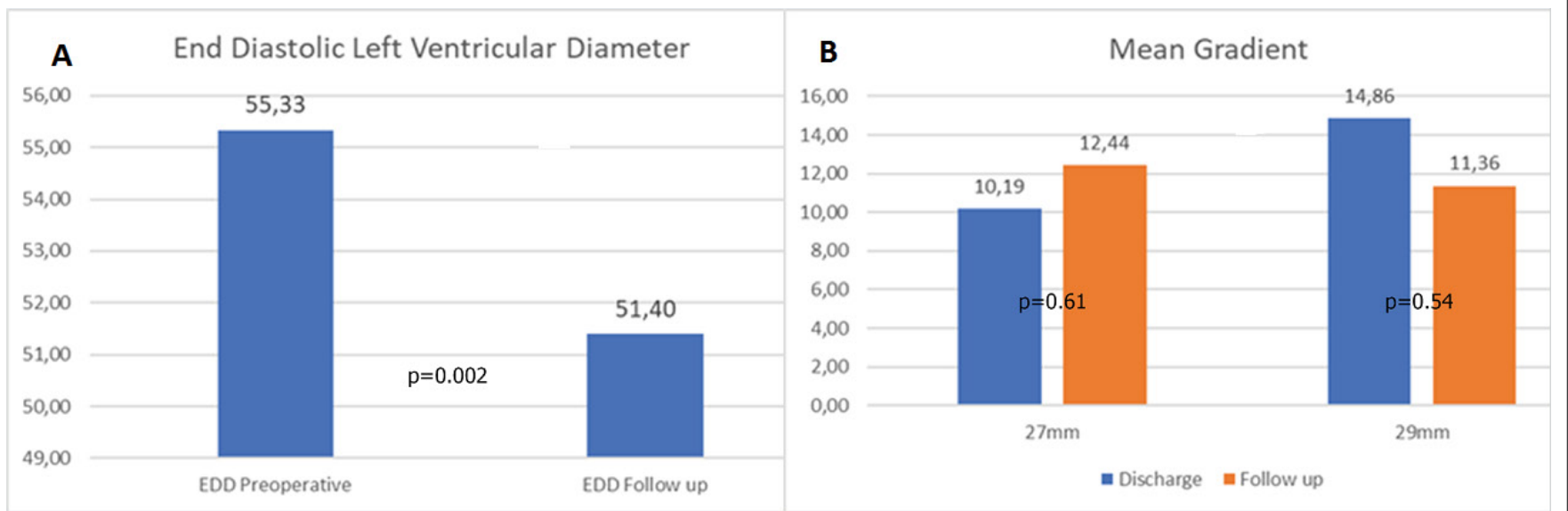

Figure 4: A) Mean and peak gradients at hospital discharge and at follow-up; B) LV end-diastolic diameter reduction and interventricular septum thickness reduction.

for this trend, an increasing number of young and active patients affected by aortic root and valve pathology more and more prefer a biological implant to enjoy a good quality of life. Self-assembled bio-conduits for aortic root replacement are currently widely used by surgeons with satisfactory early and long-term outcomes $[3,4]$. In most cases a stented bioprosthesis is included into a straight or Valsalva ${ }^{\circledR}$ tube graft, in a quite simple fashion, and secured to the ventricular ouflow by interrupted or continuous sutures [5]. As an alternative technique, Albertini, et al. proposed several years ago the 'double sewing ring technique' in order to simplify the reoperation in case of SVD, and since, this surgical strategy is adopted by most surgeon [6]. Next to selfassembled bio-conduits, some ready to use conduits containing a stentless bioprosthesis are commercially available. The Shelhigh NR-2000 ${ }^{\circledR}$ full-biological conduit has been popular among surgeon for many years, with appreciable but sometime controversial results $[7,8]$. This user-friendly device for Bentall operation was utilized with appreciable long-term results until 2008, after a US FDA immediate recall for all the Shelhigh products, including the NR-2000 conduit, mainly due to suspected lack of sterility in the environmental processes of the devices [9]. The same prosthesis with the name of Bio-Integral conduit is again available on the European market since few years end is currently in use [10]. The second readyto-use bio-conduit is a stentless porcine valve embodied into a three-layered Valsalva graft, the Bio-Valsalva. Kaya, et al. [11] reported encouraging early results in a cohort of 102 patients undergoing a Bentall procedure with this prosthesis. Similar early results with the same conduit were reported by other authors [12-15].

In 2010 Stewart, et al. presented their early results after Bentall operation carried out by using a novel bio-conduit assembled with a $3 \mathrm{~F}$ stentless bioprosthesis incorporated in a Valsalva tube graft [16]. They emphasized several advantages related to this device, like excellent hemodynamic performances, the possibility to insert a large prosthesis virtually in any patient, and the potential of easier reintervention related to the adopted double sewing ring technique $[17,18]$. Taking advantage from other's and our personal experience with more than $120 \mathrm{implants}$ of $3 \mathrm{~F}$ prosthesis, a stentless valve made by three equal sections of equine pericardium assembled in a tubular structure on a thin polyester sewing ring [19], we began to implant the self-assembled 3F bioroot in 2010 , using the previously described surgical technique. Unlike Stewart's conduit, we preferred to use a straight tube graft instead of Valsalva graft. We believed that, because of its unique tubular geometry and the importance of keeping the commissural tabs in a vertical alignment, the $3 \mathrm{~F}$ valve could perform better in a straight graft rather than into a Valsalva graft due to more physiologic distribution of leaflets stress, theoretically reducing the incidence of premature structural failure. This detail is illustrated in Figure 5. However, the use of Valsalva graft may be helpful to reduce the risk of a subsequent valve-in valve procedure. The use of straight graft in $3 \mathrm{~F}$ bioroot was based on our encouraging long-term results in terms of preserved valve function, of reimplantation operation achieved by using straight tube prosthesis. In the last part of our experience, according to the concept 'one size fits all', the conduit was pre-assembled, significantly saving ECC and ACC time (Figure 6). To our knowledge, this is the longest follow-up after self-made $3 \mathrm{~F}$ bio-root implantation reported to-date in literature. Our results endorse the remarks of Stewart, et al. concerning the low transvalvular gradients observed after implant of $3 F$ bio-root, in our experience a finding quite stable over time, A paper published in 2012 by Leung Wai Sang, et al. from Montreal, Canada, raised an important question related to falsely elevated gradients by echo examination after $3 \mathrm{~F}$ valve implantation, a problem we encountered occasionally during our experience with this prosthesis, and probably related to the unique tubular design of $3 \mathrm{~F}$ prosthesis [20]. They presented three cases of patients implanted with $3 \mathrm{~F}$ in whom the postoperative transthoracic echo diagnosed the presence of a severe prosthetic stenosis, in contrast with the heart catheterization findings of negligible 

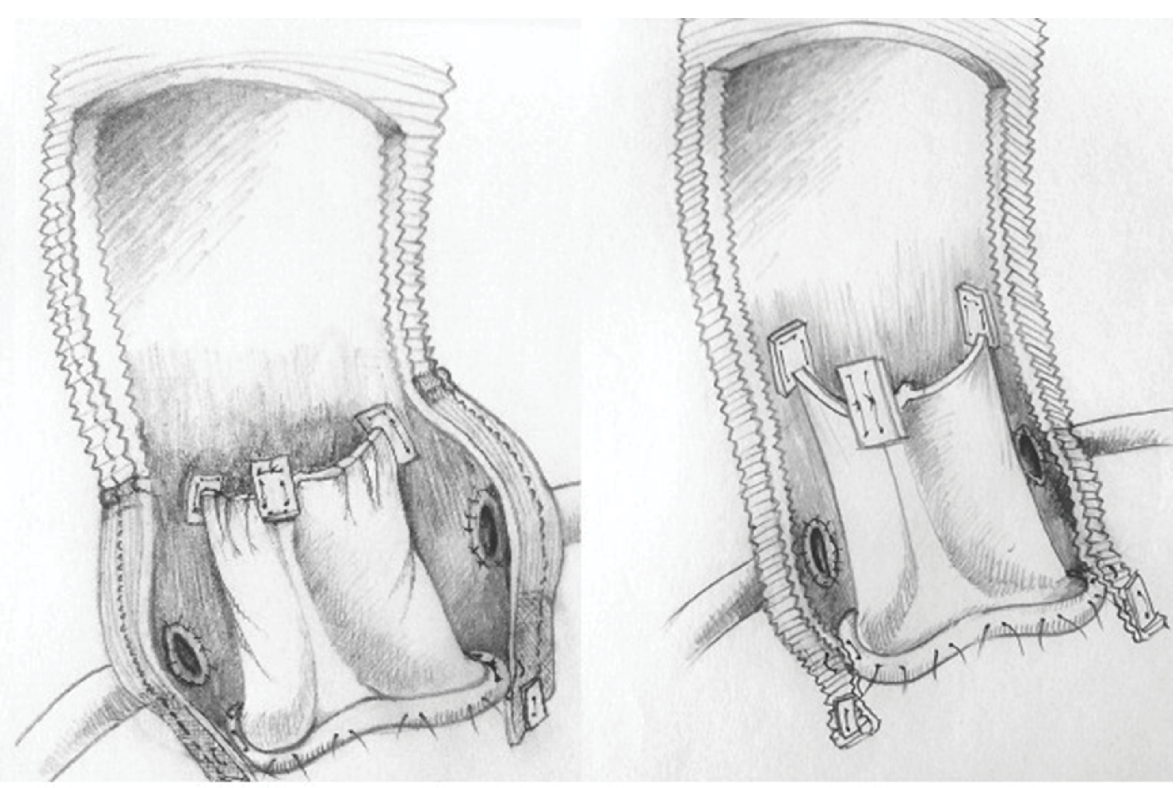

Figure 5: 3F Bio-root. Valve inclusion in Valsalva prosthesis (left) and in straight prosthesis (right), different alignment of prosthetic tabs after implant-oblique (Valsalva), vertical (straight).

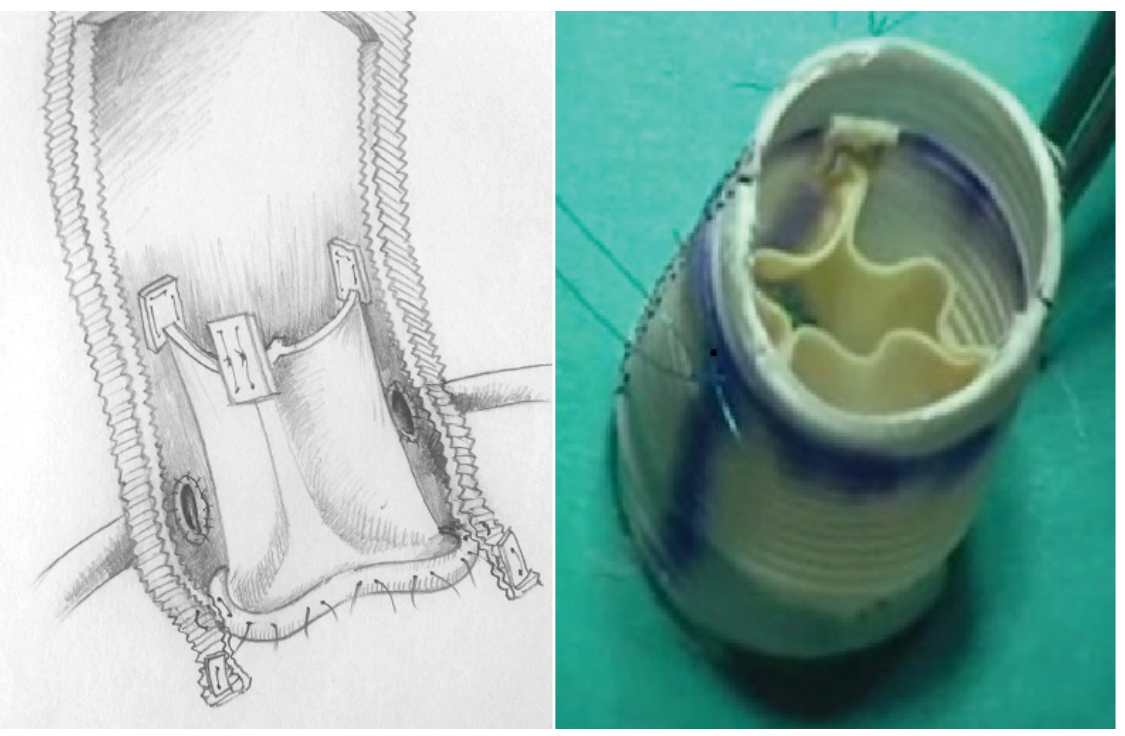

Figure 6: Drawing of 3F Stentless bio-conduit (left). The assembled bio-root before implantation (right).

transvalvular gradients. In our opinion the unexpected observation of post-operative peak and mean gradients after $3 \mathrm{~F}$ bio-root implantation, moreover higher in $29 \varnothing$ prosthesis when compared to $27 \varnothing$, and improved at follow-up echo findings, might be explained by this drawback. Therefore great caution must be taken when interpreting echo-derived gradients in patients implanted with $3 \mathrm{~F}$ prosthesis. One patient in our series underwent a valve related reoperation three years after surgery because of acute aortic incompetence secondary to spontaneous polypropylene fracture and partial detachment of a portion of prosthetic sewing ring from the graft, generating a huge perivalvular leak. We were able to reattach the prosthesis inflow to the graft with four mattress stitches, restoring a normal valve function. The operation was uneventful and his aortic valve was working perfectly at last follow-up control.
This case series highlights the long lasting hemodynamic performance of $3 \mathrm{~F}$ prosthesis, thus delaying the need for further interventions. Anyway, several reports of increasing numbers of valve-in valve procedures achieved in patients suffering from structural valve degeneration of similar stentless device is available in the more recent literature, and demonstrates growing experience and excellent results in the treatment of this subset of patients

Unfortunately, we had to shut down the implantation of $3 \mathrm{~F}$ bioroot in 2015, when, for business strategies, Medtronic interrupted the 3F and 3F-Enable production. However, we believe that our experience with $3 \mathrm{~F}$ conduit reported in this study may have an historical relevance and may be of translational value for other commercially available or self- assembled stentless bioroots. 


\section{Limitations}

The limitation of this study is inherent in its retrospective design and related disadvantages of selection bias, besides the small numbers of the cohort. However, the consecutive patients selection and the single-surgeon, single-institution experience should partially reduce these bias.

\section{Conclusions}

In our experience the 3F bioroot represented a novel self-assembled biological device useful for buttonBentall operation with some additional advantages compared to other bio-conduits. Larger size of implant, excellent hemodynamics, easier reintervention in case of prosthetic replacement for SVD and possible extended durability, made of $3 \mathrm{~F}$ bio-root a reliable self-assembled conduit for Bentall procedures. Intermediate-term survival, incidence of device-related complications, SVD, valve related reoperations and hemodynamic performances stable over time are comparable to other readily available or self-made bio-conduit used currently in use for Bentall procedures.

\section{Declarations}

\section{Ethics approval and consent to participate}

The study was approved by the Institutional Ethical Committee, verbal informed consent to use their data was obtained from all patients and approved by Ethical Committee. Guidelines reported by Akins, et al. were used to define the endpoints of the analysis.

\section{Availability of data and material}

Preoperative, intra-operative and postoperative data were collected from the hospital medical records.

\section{Competing of interest}

The authors have no conflicts of interest to declare.

\section{Funding}

No funding was provided.

\section{Aknowledgements}

None.

\section{Statement}

The authors declare that any research material related to this paper can be accessed on request in accordance with current privacy regulations. All authors have read and approved the manuscript.

\section{References}

1. Kouchoukos NT, Wareing TH, Murphy SF, Perrillo JB (1991) Sixteen-year experience with aortic root replacement. Results of 172 operations. Ann Surg 214: 308-318.

2. Bentall H, DeBono A (1968) A technique for complete replacement of the ascending aorta. Thorax 23: 338-339.

3. Urbanski PP (1999) Replacement of the ascending aorta and aortic valve with a valved stentless composite graft. Ann Thorac Surg 67: 1501-1502.

4. Badiu CC, Bleiziffer S, Eichinger WB, Hettich I, Krane $M$, et al. (2011) Long-term performance of the Hancock bioprosthetic valved conduit in the aortic root position. J Heart Valve Dis 20: 191-198.

5. Tabata M, Takayama H, Bowdish ME, Smith CR, Stewart AS (2009) Modified Bentall operation with bioprosthetic valved conduit: Columbia University experience. Ann Thorac Surg 87: 1969-1970.

6. Albertini A, Dell'Amore A, Zussa C, Lamarra M (2007) Modified Bentall operation: The double sewing ring technique. Eur J Cardiothorac Surg 32: 804-806.

7. Galiñanes M, Meduoye A, Ferreira I, Sosnowski A (2011) Totally biological composite aortic stentless valved conduit for aortic root replacement: 10 -year experience. $J$ Cardiothorac Surg 6: 86.

8. Carrel TP, Schoenhoff FS, Schmidli J, Stalder M, Eckstein FS, et al. (2008) Deleterious outcome of no-react-treated stentless valved conduits after aortic root replacement: Why were warnings ignored? J Thorac Cardiovasc Surg 136: 52-57.

9. Stefanelli G, Pirro F, Macchione A, Bellisario A, Weltert L (2020) Long-term follow-up after Bentall operation using a stentless Shelhigh NR-2000 bio-conduit. J Card Surg 35: 988-995.

10. Raweh A (2016) Bio-Valsalva or Bio-Integral: Which biological aortic valved conduit has a better hemodynamic performance? J Clin Exp Cardiolog 7: 7.

11. Kaya A, Heijmen RH, Kelder JC, Morshuis WJ (2012) First 102 patients with the BioValsalva conduit for aortic root replacement. Ann Thorac Surg 94: 72-77.

12. Di Bartolomeo R, Botta L, Leone A, Pilato E, Martin-Suarez S, et al. (2008) Bio-Valsalva prosthesis: 'new' conduit for 'old' patients. Interact Cardiovasc Thorac Surg 7: 1062-1066.

13. Lau KKW, Bochenek-Klimczyk K, Galinanes M, Sosnowski AW (2008) Replacement of the ascending aorta, aortic root, and valve with a novel stentless valved conduit. Ann Thorac Surg 86: 278-281.

14. Moorjani N, Modi A, Mattam K, Barlow C, Tsang G, et al. (2010) Aortic root replacement using a biovalsalva prosthesis in comparison to a "handsewn" composite bioprosthesis. J Card Surg 25: 321-326.

15. Bochenek-Klimczyk K, Lau KKW, Galiñanes M, Sosnowski AW (2008) Preassembled stentless valved-conduit for the replacement of the ascending aorta and aortic root. Interact Cardiovasc Thorac Surg 7: 964-968.

16. Stewart AS, Takayama H, Smith CR (2010) Modified bentall operation with a novel biologic valved conduit. Ann Thorac Surg 89: 938-941.

17. Iribarne A, Russo MJ, Easterwood R, Yang J, Stewart AS (2011) Designing a stentless valve conduit for use in a biological bentall procedure. J Heart Valve Dis 20: 590-592.

18. Yang JA, Neely RC, Stewart AS (2013) Modified bentall procedure with composite biologic grafts. J Card Surg 28: 731-735.

19. Mueller XM, von Segesser LK (2003) A new equine pericardial stentless valve. J Thorac Cardiovasc Surg 125: 1405-1411.

20. Wai Sang Leung S, Samoukovic G, Buithieu J, DeVarennes B (2013) Falsely elevated valve gradients by echocardiography in the $3 f$ aortic bioprosthesis. Ann Thorac Surg 96: 313-317. 